\title{
Parasite communities of Adriatic cage-reared fish
}

\author{
Ivona Mladineo* \\ Institute of Oceanography and Fisheries, PO Box 500, 21000 Split, Croatia
}

\begin{abstract}
From June 2001 to March 2002, 7 semi-offshore facilities in the Adriatic Sea rearing sea bass Dicentrarchus labrax, sea bream Sparus aurata, sharpsnout bream Diplodus puntazzo and red sea bream Pagellus bogaraveo aged 1+, were monitored for the presence of protozoan and metazoan parasites. Obtained data sets of abundance and prevalence were used to evaluate the structure and dynamic of infra- and component parasite communities. In all hosts, except the red sea bream, dominant parasites were monogenean specialists, showing clear seasonality. Average infracommunity richness was very low, ranging from 1 to 3 parasites per fish, while at component community level, values ranged from 3 to 8 , depending on host species. Based on low diversity indices and a moderate to high similarity coefficient between different facilities, it can be concluded that the parasitofauna of Adriatic cage-reared fish is a stable and impoverished stochastic assemblage, with monogeneans as the predominant parasitic group.
\end{abstract}

KEY WORDS: Adriatic Sea · Cage-reared fish · Infracommunity · Component community

\section{INTRODUCTION}

Poulin (1997) defined infracommunities as assemblages consisting of all the parasite species in the individual host. These are determined by various factors and range from highly structured and predictable to purely stochastic and random. If the structure of a community can be predicted and demonstrated by statistical models, the community has a stochastic and stable prefix; if not, parasite assemblages isolated from a host are the result of a random incidence. A sum or all subsets of infracommunities define a component community, which consists of all parasite species exploiting 1 host population. One main distinction between infra- and component communities' structure and dynamics is that the latter last a few host generations (so long as the host population lives), while infracommunities last as long as their host lives.

Parasite communities, especially helminth, were widely described and modeled in recent years. However, most studies focused on the structure and changes in parasite dynamics of freshwater or/and wild fish populations (Kennedy \& Pojmanska 1996, Kennedy et al. 1997, Salgado-Maldonado \& Kennedy 1997, Kennedy 2001, De Liberato et al. 2002, Kennedy
\& Moriarty 2002). Generally speaking, helminth communities in freshwater fish tend to be isolationist in structure and stochastic in composition, reflecting their low species richness and diversity (Kennedy 1990).

In marine environments, studies concerning parasite communities are limited to a few fish species, mostly those of commercial importance: sciaenid fish (Luque 1996), flatfish (Belghyti et al. 1994, Lile 1998, Álvarez et al. 2002), sea trout (Byrne et al. 1999), conger eel (Sanmartín et al. 2000a) and an elasmobranch (undulate ray) (Sanmartín et al. 2000b). However, conclusions about the nature of the communities differ greatly.

Despite the obvious significance of cage-reared Mediterranean fish species for the market and a vast number of parasitological studies focused only on identification and pathogenesis of parasites, no studies have been published on the structure and dynamics of parasite communities in cage-reared fish. Moreover, the parasitofauna of the wild Adriatic fish population has been studied in detail only for the southern-most part of the Adriatic Sea (Radujković \& Raibaut 1989), while cage-reared fish have only been examined sporadically, in the course of disease outbreaks (Mladineo 2002, 2003). 
The scope of this study was to list parasite species, describe the type of their community in 4 commercially reared fish species and compare geographically separate parasite communities.

\section{MATERIALS AND METHODS}

Seven fish farms in the eastern Adriatic were monitored from June 2001 to March 2002 (Fig. 1)

The same fish population was followed over a 9 mo period. Fish were collected once every 3 mo from semioffshore netpens, always from the same cage. Fish samples comprised 30 individuals of each species: sea bass Dicentrarchus labrax, sea bream Sparus aurata, sharpsnout bream Diplodus puntazzo and red sea bream Pagellus bogaraveo, all aged 1+. In total, 1275 individuals were examined.

Collected fish were placed on ice and brought to the laboratory within hours, where biometrical measures were recorded and fish were autopsied. Integument,

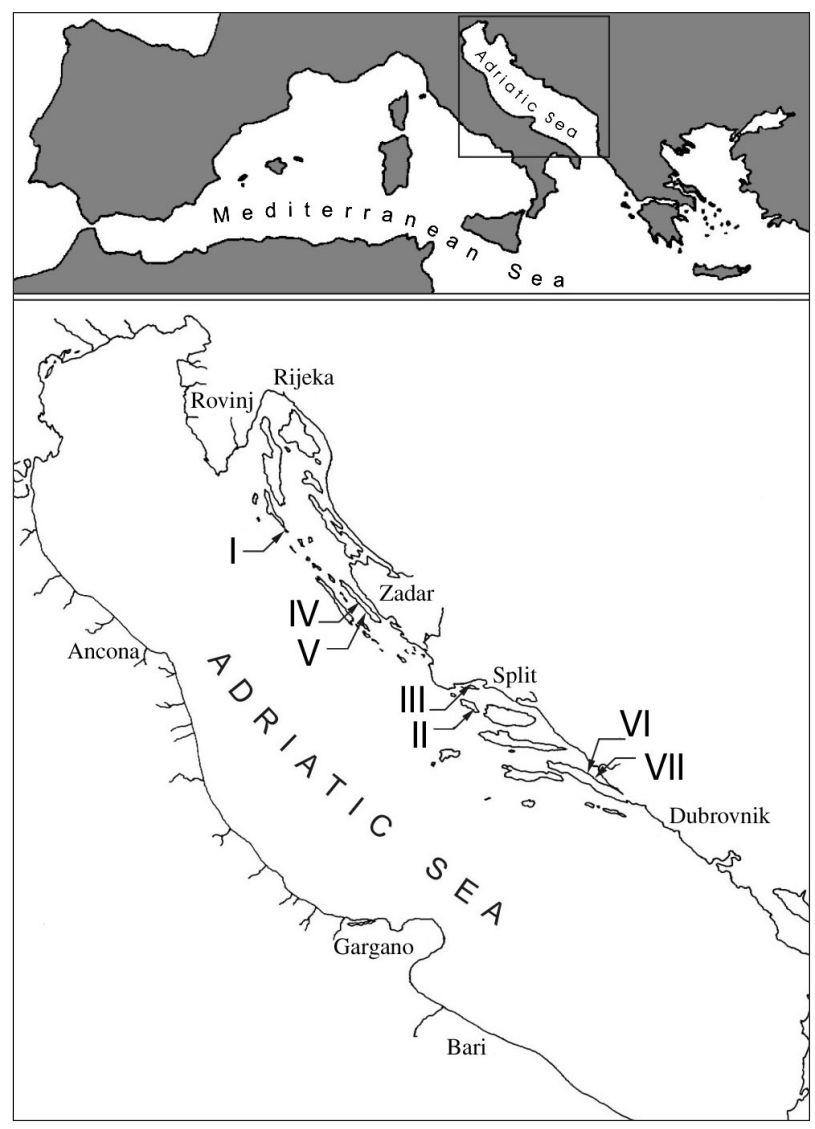

Fig. 1. Locations of monitored fish farms in the Adriatic Sea. Facility I: Kaldonta bay (Island of Cres); Facility II: Vela Luka bay (Island of Šolta); Facility III: Peleš bay (near Primošten); Facility IV: Island of Žižanj; Facility V: Island of Žižanj; Facility VI: Island of Maslinovac (peninsula of Pelješac); and Facility VII: Island of Tajan (peninsula of Pelješac) cavities and visceral organs were inspected for macroparasites.

Fresh smears from gills, skin and fins, from 3 different sections of the alimentary duct (pyloric area middle intestine and rectal part), spleen, liver, gonads and kidney were taken for examination of protozoa and myxosporea. If positive, air-dried smears were stained by May-Grünwald Giemsa. The number of protozoa was counted semiquantitatively per microscope field at $100 \times$ for Amyloodinium sp. and at $400 \times$ for myxosporea: + (10 individuals), ++ (20), +++ (30), ++++ (40) and +++++ (50) (Sitjá-Bobadilla \& AlvarezPellitero 1995). Myxosporeans were measured and identified according to Lom \& Arthur (1989).

Gill monogeneans were counted from the first gill arch under a dissecting microscope. The number was multiplied by 4 (number of gill arches) and 2 (both sides of fish), respectively.

Ecological terms describing parasitological dynamics were used according to Margolis et al. (1982). For every fish host and fish species from a particular facility, prevalence and abundance were calculated according to Bush et al. (1997).

Component community was described on the basis of the Simpson, Berger-Parker and Shannon-Wiener indices, while infra-community was described by the Brillouin index and the mean numbers of parasite species and individuals per fish. All indices were calculated according to Magurran (1988) and Krebs (1998). Similarities between indices of the different facilities were tested by the Jaccard similarity index (Salgado-Maldonado \& Kennedy 1997, Krebs 1998).

Because of inappropriate weather conditions, only inshore facilities were sampled during December 2001.

\section{RESULTS}

Parasite fauna of Adriatic cage sea bass consist of 7 parasite species (Diplectanum aequans, Polysporoplasma sparis, Sphaerospora dicentrarchi, Amyloodinium ocellatum, Cryptocaryon irritans, Ceratomyxa labracis, Ceratothoa oestroides), 8 in sea bream (Polysporoplasma sparis, Amyloodinium ocellatum, Cryptocaryon irritans, Ceratomyxa sparusaurati, Ceratothoa oestroides, Lamellodiscus elegans, Sparicotyle chrysophrii, Trichodina sp.), 6 in sharpsnout bream (Lamellodiscus elegans, Amyloodinium ocellatum, Ceratomyxa diplodae, Polysporoplasma sparis, Sparicotyle chrysophrii, Caligus minimus) and only 3 in red sea bream (Ceratomyxa diplodae, Hysterothylacium sp., Amyloodinium ocellatum). All species were previously reported and described in Mediterranean aquaculture; however, in terms of the dynamics of the parasite populations, only abundances and prevalences were 
recorded. The mean weight of the sea bass sample was $165.11 \pm 59.61 \mathrm{~g}, 255.69 \pm 126.02 \mathrm{~g}$ of the sea bream, $247.60 \pm 35.97 \mathrm{~g}$ of the sharpsnout and $198.66 \pm 45.70 \mathrm{~g}$ of the red sea bream. The overall parasitofauna with its hosts, infection site, prevalence and abundance is shown in Table 1.

In Adriatic cage sea bass, the core and dominant parasite species throughout the year and at all facilities was the monogenean specialist Diplectanum aequans, showing the expected seasonality, with maximal abundance and prevalence values in summer and fall, and decreased abundance in winter. The second most prevalent species was the myxosporean Sphaerospora dicentrarchi, also strictly a specialist, which however showed a decrease of prevalence and abundance during warm months and an increase during cold months. The satellite species were the isopode Ceratothoa oestroides and the myxosporean Caratomyxa sparusaurati, both shared with other sparid and cageneighboring species, and can thus both, but in particular the former, be termed generalists.

In the sea bream, the most prevalent species differed depending on the facility site, but in most cases another monogenean specialist, Sparicotyle chrysophrii, seemed to be the core species (in 3 out of 6 facilities where sea bream was bred). In other cases, the core species were myxosporeans Caratomyxa sparusaurati or Polysporoplasma sparis. While $S$. chrysophrii followed the seasonal pattern of increase in warm and decrease in cold periods, the myxosporeans' dynamics showed an irregular pattern depending on the facility. Interesting was a sharp proliferation of Amyloodinium ocellatum in the spring months only, which was absent during further samplings. The satellite species in this case was Trichodina sp.

In the sharpsnout bream, the core species was the specialist monogenean Lamellodiscus elegans; however, a possible switch from the sea bream could be suspected in connection with the monogenean Sparicotyle chrysophrii, which showed unexpectedly high population values. This monogenean was isolated in both facilities where the sharpsnout was bred, with proportional values of abundance and prevalence, and marked seasonality. Drastic spring proliferation of Amyloodinium ocellatum was recorded again. The sharpsnout satellite species were the copepod Caligus minimus and myxosporean Myxobolus sp.

Since the red sea bream was cultured only at 1 facility and its provenience differed from that of other cultured fish, as it was caught wild and cultured in polyculture with the sea bream, its core species was Ceratomyxa sparusaurati, as was also the case for sea bream at few of the facilities. The satellite species was the third-stage larvae of Hysterothylacium aduncum.
The mean values and standard deviations of diversity indices are shown in Table 2 .

The sea bass mean infracommunity richness was 1.95 ( \pm 1.08 ranging from 1 to maximum 5 parasite species per fish), $2.87 \pm 1.64$ in sea bream (1 to 6 ), 2.83 \pm 1.72 in sharpsnout bream ( 1 to 6 ) and $1.25 \pm 0.5$ in red sea bream. Generally, even species richness showed very low values, abundances of parasites were moderate to high and differed greatly between distant facilities. The same parameters varied among different host species reared at the same facility.

Brillouin index values were low, with the highest values in the sharpsnout bream population, where both sharpsnout samples showed no significantly different values on the Brillouin index, although the facilities were distant from each other. The greatest oscillations in Brillouin values were in sea bream populations at different facilities, while red sea bream on average showed no parasites per fish. The most uniform Brillouin was recorded among sea bass, with a very low value of 0.04 parasite species per fish.

The values of the Shannon-Wiener and Simpson's index perfectly illustrated the poor diversity of parasite species, being close to zero and 1, respectively. The sharpsnout bream population had the highest values on both indices.

The Berger-Parker dominance index was again the highest in the sharpsnout population, which reflected the extreme abundance values of the monogenean Lamellodiscus elegans, despite the poor diversity rates applicable here as elsewhere.

Similarities between component communities of sea bass, sea bream and sharpsnout from different facilities are shown in Table 3, and demonstrate considerable uniformity that in some cases reached maximum values (1). However, the overall similarity index seemed to be the highest among cage-reared sea bass $(0.725 \pm 0.11)$, as compared with the sharpsnout populations (0.667) and for the sea bream (0.651 \pm 0.08$)$.

The highest diversity of parasite species in reared Adriatic fish was found on sea bass and sea bream reared at Facility II and sharpsnout at Facility I, the latter being the host with the highest overall diversity. The lowest values of parasite diversity were recorded at Facilities VII (sea bass), V (sea bream) and III (red sea bream).

\section{DISCUSSION}

Generally, helminth communities of freshwater fish have been widely studied and are known to be species-poor, characterized by low diversity and high dominance, which makes them stochastic and isolationist (Kennedy et al. 1997). The same lack of diversity 


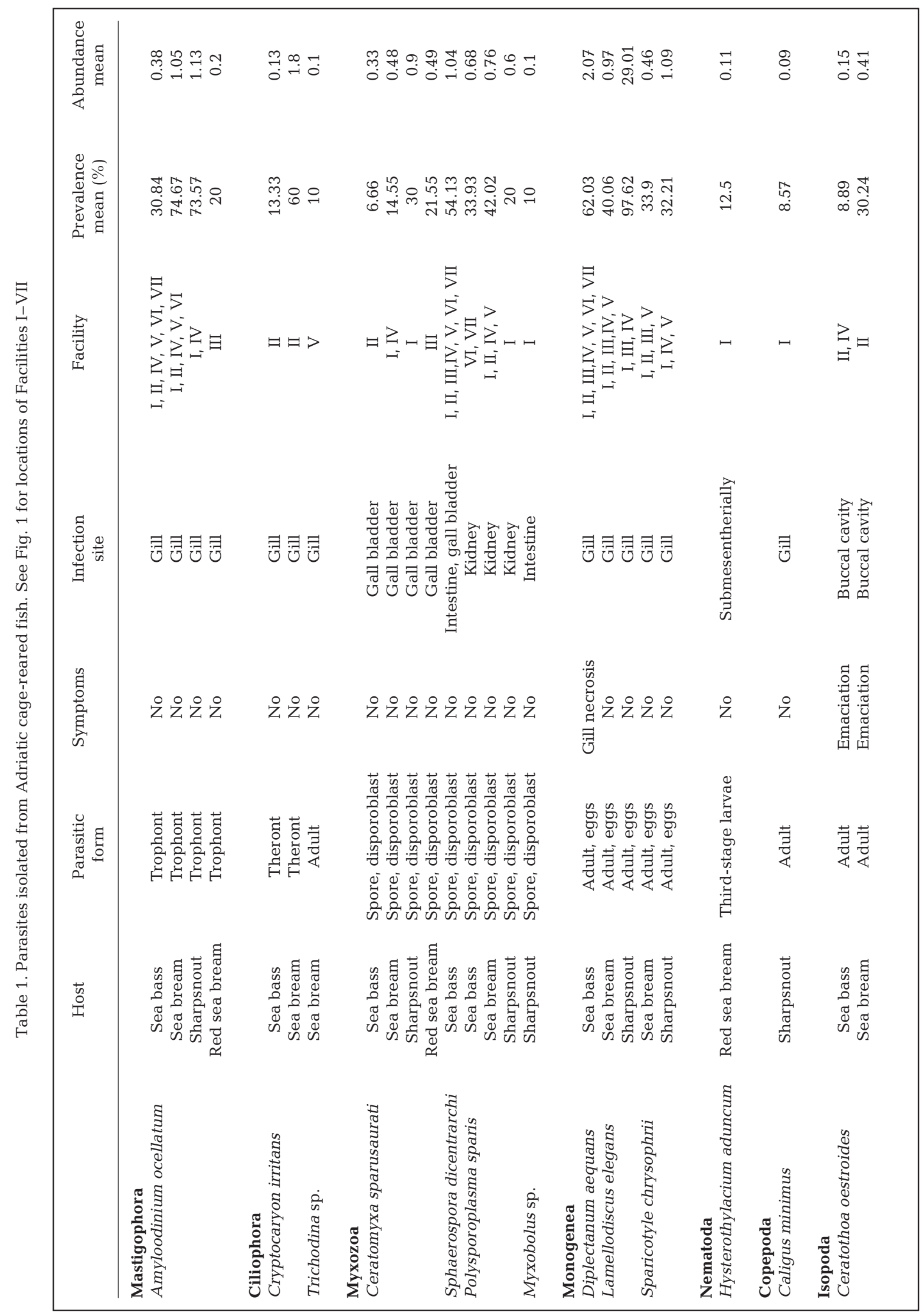


was also recorded in a freshwater environment under limited farm conditions where the more or less controlled diet is the ultimate factor restricting community diversification (Kennedy \& Pojmanska 1996).

However, in a brackish water environment species richness and diversity in parasite communities appeared to change with changes in salinity, with a decline in both these parameters reflecting an increase of salinity (Køie 1988, Kennedy et al. 1997).

When parasite communities in fish from tropical areas were evaluated, diversity was seen to differ. Salgado-Maldonado \& Kennedy (1997) reported in cichlid fish from Mexico a very rich component community with an extreme dominance of digeneans, which, in temperate areas, usually switched towards acanthocephalans (Kennedy 1993). Even in this case, marine localities differed significantly from real freshwater sites in terms of species richness, showing lower richness, dominance of marine Tetraphyllidae and a low index of similarity between the communities.

Although Kennedy (1986) stated that marine fish are likely to exhibit greater diversity in parasite communities because of their greater vagility, it is not possible to apply a clear, general pattern to all marine fish populations.

Table 2. Diversity indices (mean and standard deviation) in different hosts. H: Shannon-Wiener index; E: Brillouin index; D: Simpson's index; d: BergerParker index

\begin{tabular}{|lcccccccc|}
\hline \multirow{2}{*}{ Host } & \multicolumn{2}{c}{$\mathrm{H}$} & \multicolumn{2}{c}{$\mathrm{E}$} & \multicolumn{2}{c}{$\mathrm{d}$} & \multicolumn{2}{c|}{$\mathrm{d}$} \\
& Mean & SE & Mean & SE & Mean & SE & Mean & SE \\
\hline Sea bass & 0.04 & 0.02 & 0.04 & 0.02 & 1.06 & 0.35 & 0.96 & 0.33 \\
Sea bream & 0.15 & 0.13 & 0.16 & 0.15 & 1.18 & 0.43 & 0.98 & 0.28 \\
Sharpsnout & 0.24 & 0.03 & 0.26 & 0.08 & 1.28 & 0.23 & 0.93 & 0.12 \\
Red sea bream & 0 & 0 & 0 & 0 & 1 & 0 & 1 & 0 \\
\hline
\end{tabular}

Table 3. Jaccard coefficient of similarity between same host species reared at different facilities. See Fig. 1 for location of Facilities I-VII

\begin{tabular}{|lcccccccc|}
\hline \multirow{2}{*}{ Facility } & Host & I & II & III & IV & V & VI & VII \\
\hline I & Sea bass & & 0.6 & 1 & 0.667 & 0.75 & 0.667 & 0.667 \\
& Sea bream & & 0.636 & 0.714 & 0.833 & 0.75 & 0.556 & \\
& Sharpsnout & & & & 0.667 & & & \\
II & Sea bass & 0.6 & & 0.6 & 0.75 & 0.667 & 0.636 & 0.636 \\
& Sea bream & 6.636 & & 0.667 & 0.636 & 0.7 & 0.545 & \\
III & Sea bass & 1 & 0.6 & & 0.667 & 0.75 & 0.667 & 0.667 \\
& Sea bream & 0.714 & 0.667 & & 0.625 & 0.714 & 0.6 & \\
IV & Sea bass & 0.667 & 0.75 & 0.667 & & 0.8 & 0.714 & 0.714 \\
& Sea bream & 0.883 & 0.636 & 0.625 & & 0.667 & 0.571 & \\
& Sharpsnout & 0.667 & & & & & & \\
V & Sea bass & 0.75 & 0.667 & 0.75 & 0.8 & & 0.8 & 0.8 \\
& Sea bream & 0.75 & 0.7 & 0.714 & 0.667 & & 0.556 & \\
VI & Sea bass & 0.667 & 0.636 & 0.667 & 0.714 & 0.8 & & 1 \\
& Sea bream & 0.556 & 0.545 & 0.6 & 0.571 & 0.556 & & \\
VII & Sea bass & 0.667 & 0.636 & 0.667 & 0.714 & 0.8 & 1 & \\
\hline
\end{tabular}

The diverse and wide feeding characteristics in marine fish seem to be the prime parameter determining the structure of their parasite communities. Sanmartín et al. (2000b) isolated from undulate ray Raja undulata 9 autogenic parasite species that reflected the top position of the ray in the food chain. In pleurinectiform fish, which are domersal and feed on copepods in their earlier stage, becoming ichthyophagous later, cestode and acanthocephalan acquired from amphipodal intermediate hosts were the most dominant species (Belghyti et al. 1994). Álvarez et al. (2002) found considerably rich helminth community with 13 parasite species in other flatfish hosts; however, nematodes were dominant here. In whiting Merlangius merlangius as a pelagic species, the distribution of helminth and copepod parasites showed that digeneans were by far the most prevalent and abundant (Shotter 1976), as is typical for pelagic and predatory fish (Lile 1998).

Zander et al. (1999) isolated from 10 Baltic Sea fish species a total of 36 parasite species, with digeneans again being the most abundant. However, their infracommunity richness consisted of only 1 to 3 parasite species, similar to the results obtained in Adriatic cagereared fish. The authors agreed with Holmes (1990), who stated that rich infracommunities in marine environments are rare, with both planctivore or piscivore fish having far fewer intestinal parasites. It was not an exception that sea trout harboring 11 parasite species had infracommunity values which again were low, making the authors conclude in favour of its impoverished helminth fauna (Byrne et al. 1999).

In confined and more or less controlled rearing conditions, 'limited' diet is reflected in an absence of intestinal helminth communities. Adriatic cage-reared fish populations showed a similar pattern of parasite community dynamics to the freshwater fish, being poor in species richness at infra- and component community level. In 3 out of 4 host species, the dominant parasite species were monogeneans, with marked seasonal attributes. A similar condition was reported from 5 sciaenid fish, where ectoparasite communities were dominated by the diplectanid monogeneans (Luque 1996). Those monogeneans are specialists, parasitizing only specific reared fish species and showing an affinity for a possible host switch to 
phylogenetically related species (Desdevises et al. 2002). Their life cycle is simple and direct, so the passage from host to host is mediated by the close vicinity of the fish, ideally fulfilled under captive conditions. However, although species richness showed low values, abundances of parasites were moderate to high, proving that the rearing system provides ideal conditions for the exploitation of the host.

Most isolated parasite species and the core species were specialist, pointing to a clear distinction between the parasite populations of different hosts. A certain degree of 'sharing' of parasite species was evident only at facilities rearing phylogenetically related hosts, such as sea bream, sharpsnout bream and red sea bream.

The steadiest parasitic population was present in sea bass, which have been reared for the longest period in Adriatic, so the hypothesis of the 'native' species (in this case, sea bass in comparison with sparids) harboring stable parasite communities when compared with 'introduced' species is applicable here.

The stability of the component community is best shown by the very narrow seasonal oscillations of Shannon-Wiener and Simpson's indices during the sample year. However, a relatively high similarity coefficient also points to the generally unchangeable structure of parasite communities in reared fish. Maximum values of similarity coefficient were expected at the facilities in the close vicinity.

The 'emergence' of rare parasite species is usually connected whith major changes in (a)biotic parameters on the farm, often induced by man (transport, diet changes). In this case, it was best illustrated at Facility II, where the translocation of sea bream cages provoked a diversification of the 'common' parasite species, with infra- and component communities becoming richer.

When comparing the parasite communities in cultured common carp, Kennedy \& Pojmanska (1996) concluded that restricted feeding and restriction of fish vagility on the farm are the main reasons for the limited number of generalist helminth species and the poor parasite communities. Although wild marine fish populations tend to have a greater richness of component communities, their infracommunities are, in most cases, impoverished. The situation is more extreme in reared fish hosts, where space and food limitation severely reduced the number of parasite species and individuals, making those communities low in diversity and number.

\section{LITERATURE CITED}

Álvarez F, Iglesias R, Paramá AI, Leiro J, Sanmartín M (2002) Abdominal macroparasites of commercially important flatfish (Teleostei: Scophthalmidae, Pleuronectidae, Soleidae) in northwest Spain (ICES Ixa). Aquaculture 213:31-53

Belghyty D, Berrada-Rkhami O, Boy V, Aguesse P, Gabrion C
(1994) Population biology of two helminth parasites of flatfish from the Atlantic coast of Morocco. J Fish Biol 44: 1005-1021

Bush AO, Lafferty KD, Lotz JM, Shostak AW (1997) Parasitology meets ecology on its own terms: Margolis et al. revisted. J Parasitol 83:575-583

Byrne CJ, Holland C, Tully O (1999) Metazoan parasite community structure of sea trout on the west coast of Ireland. J Fish Biol 55:127-134

De Liberato C, Berrilli F, Di Cave D, Russo R, Tancioni L, Kennedy CR (2002) Intestinal helminths of Italian barbel, Barbus tyberinus (Cypriniformes: Cyprinidae), from the Tiber River and first report of Acanthocephalus clavula (Acanthocephala) in the genus Barbus. Folia Parasitol 49(3): $246-248$

Desdevises Y, Morand S, Legendre P (2002) Evolution and determinants of host specificity in the genus Lamellodiscus (Monogenea). Biol J Linn Soc 77:431-443

Holmes JC (1990) Helminth communities in marine fishes. In: Esche GW, Bush AO, Aho JM (eds) Parasite communities: patterns and processes. Chapman \& Hall, London, p 101-130

Kennedy CR (1986) Patterns in helminth community: why are birds and fish different? Parasitology 93:205-215

Kennedy CR (1990) Helminth communities in freshwater fish: structured communities or stochastic assemblages? In: Esch GW, Bush AO, Aho JM (eds) Parasite communities: patterns and processes. Chapman \& Hall, London, p 130-156

Kennedy CR (1993) The dynamics of intestinal helminth communities in eels Anguilla anguilla in a small stream: longterm changes in richness and structure. Parasitology 107: $71-78$

Kennedy CR (2001) Metapopulation and community dynamics of helminth parasites of eels Anguilla anguilla in the river Exe system. Parasitology 122:689-698

Kennedy CR, Moriarty C (2002) Long-term stability in the richness and structure of helminth communities in eels, Anguilla anguilla, in Lough Derg, River Shannon, Ireland. J Helminthol 76:315-322

Kennedy CR, Pojmanska T (1996) Richness and diversity of helminth parasite communities in the common carp and in three more recently introduced carp species. J Fish Biol 48:89-100

Kennedy CR, Di Cave D, Berrilli F, Orecchia P (1997) Composition and structure of helminth communities in eels Anguilla anguilla from Italian coastal lagoons. J Helminthol 71:35-40

Køie M (1988) Parasites in European eel Anguilla anguilla (L.) from Danish freshwater, brackish and marine localities. Ophelia 29:93-118

Krebs CJ (1998) Ecological methodology. 2nd edn. Addison Wesley Longman, Menlo Park, CA

Lile NK (1998) Alimentary tract helminths of four pleuronectid flatfish in relation to host phylogeny and ecology. J Fish Biol 53:945-953

Lom J, Arthur JR (1989) A guideline for the preparation of species descriptions in Myxosporea. J Fish Dis 12:151-156

Luque JL (1996) Distribution and associations in communities of ectoparasitic metazoans in marine sciaenid fishes from Peru. Rev Biol Trop 44(2A):383-390

Magurran AE (1988) Ecological diversity and its measurement. Croom Helm, London

Margolis L, Esch GW, Holmes JC, Kuris AM, Schad GA (1982) The use of ecological terms in parasitology (report of an ad hoc comittee of the American Society of Parasitologists). J Parasitol 68(1):131-133 
Mladineo I (2002) Prevalence of Ceratothoa oestroides (Risso, 1826), a cymothoid isopod parasite, in cultured sea bass Dicentrarchus labrax L. from two farms in middle Adriatic Sea. Acta Adriat 43:97-102

Mladineo I (2003) Myxosporidian infections in Adriatic cagereared fish. Bull Eur Assoc Fish Pathol 23:113-122

Poulin R (1997) Evolutionary ecology of parasites: from individuals to community. Chapman \& Hall, London

Radujković BM, Raibaut A (1989) Faune des parasites de poissons marins des côtes du Montenegro (Adriatique Sud). Acta Adriat 30(1/2):5-319

Salgado-Maldonado G, Kennedy CR (1997) Richness and similarity of helminth communities in the tropical cichlid fish Cichlasoma urophthalmus from the Yucatan Peninsula, Mexico. Parasitology 114:581-590

Sanmartín M, Álvarez MF, Peris D, Iglesias R, Leiro J (2002a) Helminth parasite communities of the conger eel in the estuaries of Arousa and Muros (Galicia, north-west Spain).

Editorial responsibility: Wolfgang Körting,

Hannover, Germany
J Fish Biol 57:1122-1133

Sanmartín M, Álvarez MF, Peris D, Iglesias R, Leiro J (2002b) Parasite community study of the undulate ray Raja undulata in the Ría of Muros (Galicia, northwest Spain). Aquaculture 184:189-201

Shotter RA (1976) The distribution of some helminth and copepod parasites in tissue of whiting, Merlangius merlangius L., from Manx waters. J Fish Biol 8:101-117

Sitjá-Bobadilla A, Alvarez-Pellitero P (1995) Light and electron microscopic description of Polysporoplasma $\mathrm{n} g$ (Myxospore, Bivalvulida), Polysporoplasma sparis n $\mathrm{sp}$ from Sparus aurata (L) and Polysporoplasma mugilis n sp from Liza aurata L. Eur J Parasitol 31(1):77-89

Zander CD, Reimer LW, Barz K (1999) Parasite communities of the Salzhaff (Northwest Mecklenburg, Baltic Sea). I. Structure and dynamics of communities of littoral fish, especially small-sized fish. Parasitol Res 85: 356-372

Submitted: February 9, 2004; Accepted: September 6, 2004 Proofs received from author(s): February 25, 2005 